\section{THE SUPPOSED MURDER.}

DR. TAYLOR's report, on the mutilated remains found at Waterloo-bridge, fully corroborates in every particular the opinions we have already expressed, and the careful descrip. tion contained in Mr. Painter's letter. (Vide Thr Lancet, October 17th.) After a very elaborate and minute investigation of all the circumstances, Dr. Taylor comes to the following

\section{CONCLUSTONS :}

1. That the remains are those of a person of the male sex, of adult age, and in stature of at least five feet nine inches.

2. That they present no physiological or pathological peculiarities by which they can be identified. The only fact observable under this head is that the portions of skin remaining are thickly covered with dark hairs on the wrist and right knee, and that the deceased was, therefore, probably a dark, hairy man.

3. That the remains present no marks of disease or of viulent injury inflicted during life, with the exception of one stab in the space between the third and fourth ribs on the left side of the chest. This stab was in a situation to penetrate the heart and to canse death. It presents the characters of a stab inflicted on a person either living or recently dead.

4. That these remains have not been dissected or used for the purposes of anatomy. All those parts which are useful to the anatomist have been roughly severed and destroyed by a person or persons quite ignorant of the anatomical relations of parts. They have been cut and sawn before the rigidity of death had ceased-i. e., from eighteen to twenty-four hours after death, and in this state have been partially boiled and subsequently salted. The body of the deceased had not been laid out or attended like that of a person dying from natural causes whose body might be lawfully used for anatomical purposes.

5 . That the person of whose body these remains are a part may have been dead for a period of three or four weeks prior to the date at which they were examined by me, namely, on the 21st of October.

The examination of the articles of clothing leads me to the conclusion that the body of the person who wore them must have been subjected to great violence. The stab penetrated from behind the double collar of the overcoat must have been inflicted with great force, as it extends through the collar of the undercoat and waistcoat. It is chiefly on the inside, and on the left side towards the left arm-pit, that the principal stains of blood are met with in the overcoat, undercoat, and waistcoat. The only wound found in the remains is a stab on the left side, which, by its situation, might have led to the effusion of blood. Assuming that the clothes belonged to the deceased, these facts appear to receive an explanation. The clothes have, however, been exposed to wet since they were stained with blood, and this creates a difficulty in forming an opinion. The cutting and tearing of the coat, trousers, and drawers at the back, and the cutting and tearing of the right sleeves of the overcoat, undercoat, and shirt, are consistent with the assumption that the body had become rigid after death in a distorted position, and that the clothes were violently torn from it. This position is indicated in the remains, especially on the right side, by the flexed or bent condition of the hip and elbow joints. Some of the stains of blood present the appearance of having flowed from a living person, and this renders it therefore probable that the clothes were on a living body when the wounds producing such effusion of blood were inflicted. While there is nothing to prove directly that these clothes were worn by the deceased, they have, in my opinion, been worn by some one who has sustained serious personal injuries. Their condition, however, is consistent with the supposition that they were actually worn by the deceased individual with whose remains they were found.

\section{To the Editor of THE LANCET.}

SIR,-Hearing a report was current, in regard to the bones found at Waterloo-bridge, " that it was only a medical student's hoax," I was induced, on the 15th inst., to write you (in defence of my young medical brethren and myself) a short and harried anatomical account of "the remains," with the hope that I might thus substantiate, in the minds of medical men, the evidence I had given, a few days previously, at the first sitting of the inquest.
In that letter I restricted myself to evident facts, and left my readers to draw their own inferences, deeming it improper in me to say anything more until after the conclusion of the inquest. I stated that at a future time I might possibly send you an account of the case in a more perfect form, and I should have done so, had not the Secretary of State deemed the matter so important as to call on Dr. Alfred Taylor to make an investigation of it. Accordingly, Professor Taylor and I having made several examinations together, he drew up a very full and lucid report, and one which so fully establishes my expressed opinions, and in which I so completely agree, that it would be a work of supererogation for me to say any more on the subject, further than that I would wish to express my high sense of the cordial manner in which Dr. Taylor has acted with me in this difficult case.

I am, Sir, your obedient servant,

Brydges-street, Covent-garden,

Rrchard Budi Painter. Oct. 29th, 1857. Surgeon F Division Metropolitan Police,

\section{Cortestrondent.}

$$
\text { "Audi alteram partem." }
$$

\section{ARMY MEDICAL DEPARTMENT. To the Editor of THE LANCET.}

Sir,-At the close of a former letter which you did me the honour to insert in THE LANCET of August 1st, I referred to the classification of diseases as contained in the Hospital Regulations of the Army, and ventured to assert that returns prepared under its guidance cannot by any possibility furnish reliable statistics; permit me to support this statement by one or two references to the Table of Diseases for Medical Returns, printed at p. 103 of the Hospital Regulations for the Army. First come Fevers. Three forms of Ague are given, but no opportunity is afforded for recording double and duplicated. cases. The fourth disease on the list is Febris Remittens Intermittens, probably a misprint. Next follows Febris Continua Communis, under which head more cases of incorrect diagnosis are registered than can well be estimated. The medical officer would be sorely puzzled if deprived of this convenient head of disease: nnder it, in army records, may be found classified any kind of ailment, from the most trifling to the most serious; from a drunkard's headache to an incurable disease. But the medical officer is not always to be made accountable for these inaccuracies. He is bound to record the name of the patient's disease on admission, or soon after, often before the real disease has developed itself, and when slight fever may be the only symptom; whereas the only mode of obtaining correct statisties would be to register the disease at the close, rather than at the commencement, of the case. It will be said that it becomes the medical officer's duty to change the name of the disease when he discovers that it is incorrectly recorded, by discharging the case under one disease and readmitting it under another; but need it be stated that by so doing he would falsify the numerical return of cases treated?

The next disease in the list is Febris Continua Ieterodes. Under this head it it probably intended to include yellow fever; but yellow fever is a remittent disease. Then follow Febris Synochus and Febris Typhus: the impression left on the mind being that these varieties are not considered to be continued fevers.

These, then, are the eight varieties under which medical officers are directed to classify fevers. How is it possible that the statistics of fever in the army can even approach accuracy?

The next head in the list is Phlegmonæ Abscessus, the only fault to be found with which is the position it occupies in the table. Then follows Paronychia: why should the table be cumbered with this? Next in order come Morbi Oculorum, likewise ill-placed; then Phrenitis; then various forms of Cynanche, several of which might be dispensed with, as being only symptoms of other constitutional diseases. We then come to one or two thoracic affections; but scattered almost promiscuously throughout the table we find the following likewise, under one or other of which medical officers are expected to classify all the diseases affecting the thoracic viscera: pneumonia, bronchitis, carditis, hæmoptysis, phthisis pulmonalis tuberculata, phthisis progressa, inflammatione thoracis, phthisis 